\title{
Profiling ellagic acid content: The importance of form and ascorbic acid levels
}

\author{
David J. Williams ${ }^{\text {a,* }}$, David Edwards ${ }^{\text {a }}$, Sharon Pun a , Mridusmita Chaliha a , Yasmina Sultanbawa ${ }^{\text {b }}$ \\ a Agri-Science Queensland, Department of Agriculture, Fisheries and Forestry (DAFF), PO Box 156, Archerfield BC, Queensland, 4108, Australia \\ ${ }^{b}$ Queensland Alliance for Agriculture and Food Innovation (QAAFI),The University of Queensland, Brisbane, Australia
}

\section{A R T I C L E I N F O}

\section{Article history:}

Received 23 May 2014

Accepted 8 September 2014

Available online 16 September 2014

\section{Keywords:}

Ellagic acid

Ascorbic acid

Dehydroascorbic acid

Strawberry

Boysenberry

Kakadu plum fruit

\begin{abstract}
A B S T R A C T
As the importance of plant-based antioxidants to human health becomes clearer there is a rapidly expanding search for rich sources of these compounds. Much attention is currently focussed on the antioxidant potential of ellagic acid (EA). Making assessment difficult is that EA occurs in different forms: free EA, EA glycosides and polymeric ellagitannins. The overall structure of these forms has a pronounced effect on their antioxidant efficiency and is responsible for widely differing reactivity, solubility and hence bioavailability properties. Often associated with EA is vitamin $C$ which also contributes to the plant foods total antioxidant activity. Previous studies have suggested that ascorbic acid may have protective effects on the polyphenol content of plants. With a view to gaining evidence that the bioactive forms of vitamin C influence EA content, several fruits with a range of EA and vitamin $C$ contents were examined. To facilitate a more detailed assessment of the selected fruits antioxidant potential the relative proportions of EA forms were also determined. In strawberries and boysenberries EA content was predominantly in the polymeric form (21\% and $12 \%$ free EA plus EA glycoside vs total EA levels for strawberry and boysenberry respectively), while in Kakadu plum it was mainly in the free form (70\% of total EA). An increasing percentage of dehydroascorbic acid ( 9 to $14 \%$ of total vitamin C) indicating enhanced transformation of ascorbic acid to its oxidative degradation product together with stable free EA levels $(\approx 950 \mathrm{mg} / 100 \mathrm{~g}$ DW) over the 4 month frozen storage period for the Kakadu plum samples are consistent with a possible protective effect of EA by ascorbic acid.
\end{abstract}

Crown Copyright $@ 2014$ Published by Elsevier Ltd. All rights reserved.

\section{Introduction}

Consumption of fruits and vegetables is known to lower the risk of several diseases, including cardiovascular diseases, cancer and stroke (Willett, 2002). Such health benefits are mainly attributed to the content of antioxidant compounds most notably vitamin C and polyphenols including gallic and ellagic acids as well as related compounds (reviewed by Crozier, Jaganath, \& Clifford, 2009). As the importance of these antioxidants to human health becomes clearer there is a rapidly expanding search for rich plant sources of these compounds with much attention focussing on the antioxidant potential of ellagic acid (EA). Ellagic acid together with the bioactive forms of vitamin $C$ (ascorbic, AA and dehydroascorbic acids, DHAA) (Fig. 1), possess double bonds with an associated electron deficiency which is highly reactive to free radicals from molecular oxygen (Atkinson, Nestby, Ford \& Dodds, 2005).

Abbreviations: AA, ascorbic acid; DHAA, dehydroascorbic acid; DPPH, 2,2-diphenyl-1picrylhydrazyl; EA, ellagic acid; ET, ellagitannins; FRAP, ferric reducing ability of plasma; ORAC, oxygen radical absorbance capacity.

* Corresponding author. Tel.: +61 7 32766041; fax: +61 732166591.

E-mail address: david.williams@daff.qld.gov.au (D.J. Williams).
Ellagic acid occurs in plants in different forms: as free EA (Fig. 1a), glycosylated via its hydroxyl groups or, most commonly, as complex polymers esterified with a sugar known as ellagitannins (ETs) (Clifford \& Scalbert, 2000). Investigations that focus on identifying EA forms in fruit and other plant materials are made more difficult by the fact that these forms differ widely in solubility and reactivity. Hydrolysis of EA glycosides or water-soluble ETs with acids or bases yields an unstable intermediate which spontaneously rearranges to the water-insoluble EA. This reaction has been utilised for the detection and quantification of total EA, with content being expressed as EA equivalents after acid hydrolysis (Rommel \& Wrolstad, 1993). The complete disappearance on acid hydrolysis but not alkaline hydrolysis provides a means of identifying and quantifying EA glycosides (Aaby, Skrede, \& Wrolstad, 2005). To determine free EA content separately, the measurement is simply performed before the hydrolysis step. The final analytic for measuring all forms is free EA (Fig. 1a).

Few studies have reported a thorough EA characterisation of fruit with most focussing on total EA content (Atkinson et al., 2005; Maas, Wang, \& Galletta, 1991; Rommel \& Wrolstad, 1993) or free EA levels (Amakura, Okada, Tsuji, \& Tonogai, 2000; Konczak, Maillot, \& Dalar, 2014). Data obtained from several studies that investigated more fully the EA forms present led to the conclusion that most plant EA was 
<smiles>O=C1Oc2c(O)c(=O)oc3c(O)c(O)cc1c23</smiles>

(a)

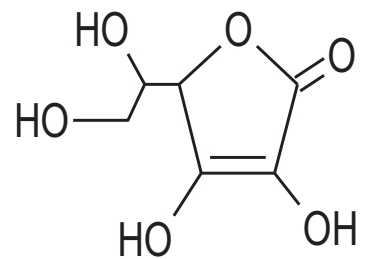

(b)

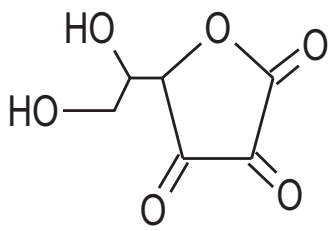

(c)

Fig. 1. Structure of (a) ellagic acid, (b) ascorbic and (c) dehydroascorbic acids.

present in the ET form with only a small proportion, if any, occurring in the free form or as EA glycosides (Aaby et al., 2005; da Silva Pinto, Lajolo, \& Genovese, 2008; Zafrilla, Ferreres, \& Tomas-Barberan, 2001) Other reports found the proportion of the free form to be highly variable with some fruit exceeding $50 \%$ of the total EA content (Rommel \& Wrolstad, 1993; Wada \& Ou, 2002).

The antioxidant efficiency of the EA forms is believed to be correlated with their degree of hydroxylation (Pfundstein et al., 2010). Zafrilla et al. (2001) reported that in red raspberries EA had the highest antioxidant activity among isolated EA glycosides, whereas an unidentified polymeric derivative showed an antioxidant capacity double that of EA. The authors stated this was expected as this latter compound possesses a far larger number of phenolic hydroxyls per molecule. Confirmation of the presence of two major ETs (sum represented 81\% of the total ETs in raspberries) was provided by Gasperotti, Masuero, Vrhovsek, Guella \& Mattivi (2010). There are also differences in bioavailability between EA forms, although these differences are the focus of numerous current investigations (reviewed in Crozier et al., 2009). Variations in bioavailability of the EA forms could explain the discrepancies observed between in vivo and in vitro experiments, with the in vitro results often failing to match the findings of the in vivo studies (see Tomás-Barberán \& Andrés-Lacueva, 2009; Tomás-Barberán, Somoza, \& Finley, 2009). The form in which EA occurs may be as important to its antioxidant activity and bioavailability as the actual content of EA. Accurate quantification of free EA, EA glycosides and ETs present in fruit, fruit-based beverages and supplements is a necessary pre-requisite for any study that evaluates their antioxidant properties and their subsequent effect on human health.

A possible link between EA and AA was recognised by Atkinson et al. (2005) when they increased these natural antioxidants in strawberries by applying enhanced radiation during growth. To date, literature reports that focus on whether the levels of endogenous bioactive forms of vitamin C (AA, and DHAA) may influence EA content in plant foods are very rare. This seems surprising as several studies showed that added AA prevented the oxidation of polyphenols even during alkaline hydrolysis (Nardini et al., 2002). A recent study by Oszmianski, Wojdyło, and Kolniak (2009) demonstrated that AA was a very useful EA oxidation protector during the storage and thawing of frozen strawberries. As AA is easily oxidisable and is very often considered a terminal oxidant (Halliwell, 1994), EA may well be protected by AA in plants.

Although several studies have measured free EA content and even more have quantified the bioactive forms of vitamin $\mathrm{C}$ in plant foods, there are, to the best of our knowledge, no studies have been carried out to gain direct evidence that AA has a protective effect on EA levels. To achieve this aim as well as gaining knowledge about the importance of structure (form) in defining its antioxidant efficiency and bioavailability we measured the free, EA glycoside and total EA content together with bioactive vitamin $C$ levels in three fruit types. The determination of $\mathrm{pH}$, titratable acidity and moisture of the fruit extracts completed the necessary characterisation. Samples of Kakadu plum fruit known to contain high levels of free EA and AA were selected for examination whilst undergoing frozen storage (Konczak et al., 2009, 2014). This approach should add to our understanding of the complex mechanisms associated with the different EA forms and their respective contribution to overall antioxidant properties and bioavailability.

\section{Materials and methods}

\subsection{Reagents}

EA, DL-homocysteine, AA and DHAA were purchased from SigmaAldrich Inc. (Sydney, NSW, Australia). The HPLC-grade methanol, formic acid, 2-propanol and acetonitrile were purchased from Thermo Fisher Scientific (Melbourne, Victoria, Australia). All other chemicals were of analytical grade and purchased from Thermo Fisher Scientific.

\subsection{Plant materials and preparation}

Recently harvested (Spring, September 2013) strawberries (Fragaria ananassa cv. Camarosa) were obtained from a commercial grower located to the south of Brisbane, Qld, Australia, frozen and stored in polyethylene bags at $-20^{\circ} \mathrm{C}$.

Frozen packs ( $1 \mathrm{~kg}$ ) of New Zealand grown boysenberries (Rubus ursinus x idaeus) were obtained from Harvestime Qld. (Yatala, Qld, Australia). Samples were kept frozen $\left(-20^{\circ} \mathrm{C}\right)$ until processing and analysis.

Commercially available whole Kakadu plum fruit (Terminalia ferdinandiana) were obtained from Australian Produce Company (Brisbane, Qld,Australia). Individual whole fruit (harvested in late Autumn, May 2012) were placed in polyethylene bags, vacuum sealed and blast frozen then stored at $-20^{\circ} \mathrm{C}$.

Sub-samples (comprising $\approx 20$ individual fruit for all three fruit types) for EA and vitamin C analysis were freeze-dried, finely ground (including the seed for the Kakadu plum whole fruit samples) in a Retsch MM301 cryomill (Retsch GmbH, Haan, Germany) and subsequently stored at $-20^{\circ} \mathrm{C}$.

For the storage trial samples of Kakadu plum were stored whole at $-20^{\circ} \mathrm{C}$. After $0,1,4,5$ and 8 months storage samples (comprising $\approx 10$ individual fruit for each individual sampling date) were manually de-seeded, freeze-dried and finely ground prior to determining moisture, free $\mathrm{EA}$ and vitamin $\mathrm{C}$ content.

\subsection{Moisture content of the freeze-dried fruit powders}

The moisture content of the freeze-dried fruit powders was determined according to AOAC (1995), official method 964.22. Briefly, in triplicate, each sample ( $1 \mathrm{~g}$ ) was dried for approximately $16 \mathrm{~h}$ to a constant weight at $70{ }^{\circ} \mathrm{C}$ in a vacuum oven (W. C. Heraeus GmbH, Hanau, Germany). The difference between initial weight and constant weight 
after drying was taken as moisture lost and hence moisture content of the sample.

\subsection{Extraction of free $E A$}

An extracting solution of $100 \%$ methanol was used for these assays. The extraction method adopted was based on that of Amakura et al. (2000) without the acidified methanol assisted solid-phase extraction (SPE) clean-up.

Triplicate samples ( $0.2 \mathrm{~g}$ for the boysenberry and strawberry freeze-dried powders; $\sim 0.1 \mathrm{~g}$ for Kakadu plum powders) were accurately weighed into a $15 \mathrm{ml}$ centrifuge tube and $3 \mathrm{ml}$ or $5 \mathrm{ml}$ (for the Kakadu plum samples) ( $3 \times$ extractions) of the extracting solvent were added and sonicated for $10 \mathrm{~min}$. The mixture was centrifuged $(\approx 3220 \times \mathrm{g}$, $5 \mathrm{~min}$ at $20^{\circ} \mathrm{C}$ ) and the clear supernatant was transferred to a $10 \mathrm{ml}$ or $25 \mathrm{ml}$ (for the Kakadu plum samples) volumetric flask and made to volume with extracting solvent. About $1.5 \mathrm{ml}$ of the diluted supernatant was filtered through a $0.45 \mu \mathrm{m}$ syringe filter into a HPLC vial, $\mathrm{N}_{2}$ was introduced, capped and stored at $-80^{\circ} \mathrm{C}$ prior to analysis.

The concentration of the extracted EA was monitored by HPLC-DAD as detailed below (Section 2.6).

\subsection{Extraction and hydrolysis of EA glycosides and ETs}

Alkaline hydrolysis of the solvent extracts and subsequent quantification was performed according to Aaby et al. (2005). Briefly, an aliquot $(2 \mathrm{ml})$ of the free ellagic-methanol extract was dissolved in $10 \mathrm{ml}$ $10 \%(\mathrm{w} / \mathrm{v}) \mathrm{KOH}$ in a $20 \mathrm{ml}$ screw-top test tube with a Teflon-lined cap and allowed to react at room temperature for $90 \mathrm{~min}$. The extracts were adjusted to $\mathrm{pH} 5.5$ with $2 \mathrm{~N} \mathrm{HCl}$. After hydrolysis the vial contents were transferred into a $10 \mathrm{ml}$ volumetric flask and made up to the mark with $100 \%$ methanol. About $1.5 \mathrm{ml}$ of this solution was filtered through a $0.45 \mu \mathrm{m}$ syringe filter into a HPLC vial, $\mathrm{N}_{2}$ was introduced, capped and stored at $-80{ }^{\circ} \mathrm{C}$ prior to analysis.

Acid hydrolysis of the methanol extracts and subsequent quantification was performed according to da Silva Pinto et al. (2008). Briefly, an aliquot $(2 \mathrm{ml})$ of the free ellagic-methanol extract was pipetted into $5 \mathrm{ml}$ Reacti-Therm (Thermo Fisher Scientific, Bellefonte, PA, USA) vial containing a stirring slug. The methanol was evaporated under nitrogen before $2 \mathrm{ml}$ of $2 \mathrm{~N}$ tri-fluoroacetic acid (TFA) was added to the vial which was then capped and mixed to dissolve the residue. The vial was placed into the Reacti-Therm heater/stirrer unit (Thermo Fisher Scientific, Bellefonte, PA, USA) where the contents were hydrolysed at $120{ }^{\circ} \mathrm{C}$ for $120 \mathrm{~min}$. After hydrolysis the vial was cooled and the contents transferred into a $5 \mathrm{ml}$ volumetric flask with $100 \%$ methanol. About $1.5 \mathrm{ml}$ of this solution was filtered through a $0.45 \mu \mathrm{m}$ syringe filter into a HPLC vial, $\mathrm{N}_{2}$ was introduced, capped and stored at $-80^{\circ} \mathrm{C}$ prior to analysis.

\subsection{HPLC-DAD analysis}

The HPLC conditions used in this study were based on those outlined by Gasperotti et al. (2010).

Samples were analysed using a Shimadzu (Shimadzu Co., Kyoto, Japan) HPLC system consisting of a system controller (SCL-10Avp), degasser (DCU-14A), pump (LC-10ATvp), auto-sampler (SIL-20ATHT), column oven (CTO-10Avp) and a photo-diode array detector (SPDM10Avp) linked to Labsolutions software. Optimal separation of the EA was achieved on a reversed-phase $C_{18}$ Acclaim, $3 \mu \mathrm{m}, 4.6 \times$ $150 \mathrm{~mm}$ column (Thermo Fisher Scientific) with matching guard column. Both columns were maintained at $30{ }^{\circ} \mathrm{C}$. Optimal separation required gradient elution. The solvents consisted of (A) $0.1 \%$ formic acid $(\mathrm{v} / \mathrm{v})$ in water and $(\mathrm{B}) 0.1 \%$ formic acid $(\mathrm{v} / \mathrm{v})$ in acetonitrile. The gradient began isocratically with $15 \%$ solvent $B$ for $1 \mathrm{~min}$, followed by a linear gradient from 15 to $20 \%$ B for $20 \mathrm{~min}$, from 20 to $90 \%$ B for $2 \mathrm{~min}$ and then isocratic for $4 \mathrm{~min}$. Re-equilibration steps over $8 \mathrm{~min}$ returned the system to initial conditions. A flow rate of $1.5 \mathrm{ml} / \mathrm{min}$ was maintained for each step.

An aliquot of $10 \mu \mathrm{l}$ of sample was injected. Spectra for all wavelengths between 220 and $600 \mathrm{~nm}$ were recorded by the photodiode array detector. The different EA forms were identified by their chromatographic behaviour, UV spectra and response to acidic and alkaline hydrolysis. Quantification (before and after acid - alkaline hydrolysis) was performed by comparison to EA commercial standards prepared in $100 \%$ methanol. An estimation of ET levels was calculated by subtracting the content of the other two forms from the total EA measurement. EA content for all three forms was expressed as $\mathrm{mg} / \mathrm{g} \mathrm{DW}$ (dry weight) after moisture determinations.

\subsection{Extraction of $A A$ and $D H A A$}

To determine both forms of vitamin $\mathrm{C}$ a two-step subtraction approach was employed. Firstly, the content of AA was determined by HPLC with UV-detection of the original sample to obtain the initial concentration. Reduction of DHAA to AA was performed by the addition of DL-homocysteine. After this conversion the samples were analysed for total vitamin C again by HPLC with UV-detection. The methods for sample preparation and HPLC analysis adopted in this study were based on those outlined by Dennison, Brawley, and Hunter (1981), Gökmen, Kahraman, Demir, and Acar (2000) and Hoare, Jones, and Lindsay (1993).

AA was determined by weighing $100 \mathrm{mg}$ of the freeze-dried fruit sample into a $15 \mathrm{ml}$ centrifuge tube followed by $10 \mathrm{ml}$ of extracting solution consisting of $1 \%(\mathrm{~m} / \mathrm{v})$ citric acid containing $0.05 \%(\mathrm{~m} / \mathrm{v})$ ethylenediamine tetra-acetic acid (EDTA) as the disodium salt in $50 \%$ $(\mathrm{v} / \mathrm{v})$ methanol. After being shaken by hand the tubes were centrifuged at $\approx 3220 \times \mathrm{g}$ for $5 \mathrm{~min}$ and $1 \mathrm{ml}$ of clear supernatant was added to a $50 \mathrm{ml}$ volumetric flask and made to volume with extracting solution. An aliquot of this solution was filtered through a $0.45 \mu \mathrm{m}$ syringe filter prior to HPLC analysis.

Total vitamin C was determined by weighing $100 \mathrm{mg}$ of sample followed by adding $4 \mathrm{ml}$ of $0.8 \%$ DL-homocysteine $(\mathrm{m} / \mathrm{v})$ to a $15 \mathrm{ml}$ centrifuge tube and adjusting the $\mathrm{pH}$ to 7 with $45 \% \mathrm{~K}_{2} \mathrm{HPO}_{4}(\mathrm{~m} / \mathrm{v})$ solution. After $15 \mathrm{~min}$ the solution was made to approximately $10 \mathrm{ml}$ with extracting solution. Again the tubes were mixed and centrifuged at $\approx 3220 \times \mathrm{g}$ for $5 \mathrm{~min}$ and $1 \mathrm{ml}$ of clear supernatant was added to a $50 \mathrm{ml}$ volumetric flask and made to volume with extracting solution. An aliquot of this solution was filtered through a $0.45 \mu \mathrm{m}$ syringe filter prior to HPLC analysis.

\subsection{Determination of ascorbic and dehydroascorbic acid content}

Separation of AA was achieved with a Waters (Waters Associates, Rydalmere, NSW, Australia) HPLC system consisting of a pump (LC-515), auto-sampler (Plus 717), UV-visible detector (model 481) linked to Varian Star software (Version 6.41). A $5 \mu \mathrm{m}$ Supelcosil LC-NH $\mathrm{N}_{2}, 4.6 \times 250 \mathrm{~mm}$ column (Supelco, Sigma Aldrich, Sydney, NSW, Australia) efficiently separated ascorbic acid isocratically by using a solution of 40:60 (v/v) methanol: $0.25 \% \mathrm{~K}_{2} \mathrm{HPO}_{4}(\mathrm{~m} / \mathrm{v})$ buffer (adjusted to $\mathrm{pH} 3.5$ with phosphoric acid) as mobile phase. The flow rate was $1.0 \mathrm{ml} / \mathrm{min}$. An aliquot of $10 \mu \mathrm{L}$ of sample was injected and the AA peak was detected at $245 \mathrm{~nm}$ and identified and quantified by comparison to a commercial standard.

Serial dilutions containing $10-100 \mathrm{mg} / \mathrm{l}$ were prepared by dissolving reference grade AA in extracting solution. A calibration curve of peak area versus standard AA concentration was plotted and the concentration of $A A$ and total vitamin $C$ was determined after applying the appropriate dilution factor. The DHAA concentration was calculated by subtracting the AA value from total vitamin $C$. The total vitamin C, AA and DHAA concentrations of the samples were expressed as $\mathrm{mg} / 100 \mathrm{~g}$ DW. 


\subsection{Determination of $\mathrm{pH}$ and titratable acidity}

The $\mathrm{pH}$ and titratable acidity (TA) of the fruit purees were measured according to the method outlined by Fredrich (2005). After defrosting the frozen sample in a microwave (as recommended by Oszmianski et al., 2009 to reduce drip loss and the possibility of chemical deterioration) the fruit was macerated in a Black \& Decker BMC 100 blender (Black \& Decker, Mooroolbark, Vic, Australia) at $100 \mathrm{rpm}$ for $2 \mathrm{~min}$. A TPS labCHEM-pH meter (TPS Pty Ltd, Springwood, Qld, Australia) was used for the determination of $\mathrm{pH}$ values of these macerated fruit samples. Following centrifugation $(\approx 3220 \times \mathrm{g}$, $5 \mathrm{~min}) 5 \mathrm{ml}$ of supernatant was pipetted into a beaker with $50 \mathrm{ml}$ of distilled water. A stirrer bar was added and the solution was titrated with $0.01 \mathrm{~N} \mathrm{NaOH}$ solution to an end-point of $\mathrm{pH}$ 8.2. The titratable acidity in terms of standard acid was calculated using the equation given below:

$\mathrm{TA}(\mathrm{g} / 100 \mathrm{ml})=\frac{(\mathrm{V})(\mathrm{N})(\mathrm{meq} \cdot \mathrm{wt} .)(100)}{(1000)(\mathrm{v})}$

$\mathrm{V}$ - volume of $\mathrm{NaOH}$ used ( $\mathrm{ml}$ ); $\mathrm{N}$ - normality of $\mathrm{NaOH}$ used; meq. wt. milliequivalent weight of the standard; and $\mathrm{v}$ - sample volume $(\mathrm{ml})$. Citric acid was selected as the standard acid for these calculations after consulting Table G2.1.1 in Fredrich (2005).

\subsection{Statistical analysis}

All analyses were run in triplicate and were expressed as means \pm standard deviation (SD). Statistical analysis was performed by using the XLSTAT-Pro software package version 7.0 (XLSTAT Addinsoft, Paris, France). Differences between means were first analysed by the ANOVA test and then least significant differences (LSD) test $(\mathrm{p}<0.05)$.

\section{Results and discussion}

\subsection{Free, EA glycoside and total EA content}

The level of free EA was $4.8 \pm 0.1 \mathrm{mg} / 100 \mathrm{~g}$ DW in strawberries, $5.5 \pm 0.6 \mathrm{mg} / 100 \mathrm{~g} \mathrm{DW}$ in boysenberries and $620.6 \pm 2.2 \mathrm{mg} / 100 \mathrm{~g}$ DW in the Kakadu plum (Table 2). Our result for the free EA content of strawberries (cv. Camarosa) is lower than the value reported by da Silva Pinto et al. (2008) who also analysed the same cultivar (22 mg/100 g DW). Similarly the value of $14.7 \mathrm{mg} / 100 \mathrm{~g} \mathrm{DW}$ for fresh strawberry (cultivar not stated) as given by Amakura et al. (2000) was also higher than our result. On the other hand our result was slightly higher than those reported by Aaby et al. (2005) of 2.2 and $3.3 \mathrm{mg} / 100 \mathrm{~g}$ DW for the strawberry cultivars Puget Reliance and Totem, respectively. Note for ease of comparison the fresh weight of some of these results were converted to dry weight on the application of the water content of $90.95 \%$ obtained after consultation of the USDA National Nutrient Database (2013).

Until recently there had been limited information on EA content of Kakadu plum. Cunningham, Garnett, Gorman, Courtney, and Boehme (2009) stated that the fruit of T. ferdinandiana is a good source of EA without providing values. However, a comprehensive recent investigation measured the levels of free EA in 567 samples of Kakadu plum fruit obtained from 45 growth sites across northern Australia (Konczak et al., 2014). They reported levels from 3050 to $14020 \mathrm{mg} / 100 \mathrm{~g}$ DW, much higher than the content shown in our extracts. In characterising the phenolic compounds present in the fruit of related Terminalia species, Pfundstein et al. (2010) reported a range of 228-410 mg/100 g DW for the free EA content, only slightly lower than our values for T. ferdinandiana. Discrepancies between research groups in measuring EA are not entirely unexpected as most have noted that EA values (even for the same plant material) vary markedly, the differences being attributed to the type and $\mathrm{pH}$ of the extracting solvents used (da Silva Pinto et al., 2008; Häkkinen \& Törrönen, 2000). Irrespective of these differences, values presented prove that Kakadu plum fruit is a very rich source of this important phytochemical.

The lack of commercially available standards makes the differentiation of EA glycosides from the more complex form, ETs, problematic. Possible glycoside compounds in the fruit extracts were identified from their chromatographic behaviour, UV spectra and response to acidic and alkaline hydrolysis and then quantified as EA (Aaby et al., 2005; Zafrilla et al., 2001). This probably accounts for there being only limited data on the levels of EA glycosides present in fruit. For the strawberry and boysenberry extracts the glycoside contents were two to three times order of magnitude higher than the free EA (Table 2). This agrees closely with the findings of Aaby et al. (2005) in their study of strawberries particularly so for the glycoside level shown by the cultivar Puget. To date there seems to be no reports outlining the levels of EA glycosides in boysenberries. In the 2002 investigation, Wada and $\mathrm{Ou}$ did not individually quantify EA glycosides or ETs but combined them as total EA. We failed to detect any EA glycosides in the Kakadu plum fruit which seems at variance with the values reported on related Terminalia species fruit by Pfundstein et al. (2010). The EA glycoside levels measured in their study ranged between $20-232 \mathrm{mg} / 100 \mathrm{~g}$ DW although it was substantially lower than that of the free form.

The value of $420 \mathrm{mg} / 100 \mathrm{~g}$ DW reported by da Silva Pinto et al. (2008) for total EA content of the strawberry cultivar Camarosa is far higher than the value for the same cultivar found in our study $(64.3 \pm 2.0 \mathrm{mg} / 100 \mathrm{~g}$ DW; Table 2$)$. However, it falls within the range (43-464 mg/100 g DW) previously reported by Maas et al. (1991) for the total EA content of strawberry fruit samples taken from 36 cultivars. Again the moisture conversion factor obtained from the USDA National Nutrient Database (2013) was applied.

A literature value of total EA content of boysenberries (496 mg/100 g DW) reported by Wada and Ou (2002) is a lot higher than that measured in our study $(168.4 \pm 3.0 \mathrm{mg} / 100 \mathrm{~g} \mathrm{DW})$ but there seems to be confusion with the actual units expressed in their report.

In the current study the total EA content of the Kakadu plum extracts was a very high $879.6 \pm 15.6 \mathrm{mg} / 100 \mathrm{~g}$ DW (Table 2).

The percentage of free to total EA levels for the strawberries (7.4\%), boysenberries (3.3\%) and Kakadu plum (70.6\%) was calculated using the above measurements (Table 2). This value for the strawberry cultivar Camarosa is in close agreement with that of da Silva Pinto et al. (2008) (5.2\%) for the free EA contribution. In our study free EA constituted only a minor part of the total EA pool of boysenberries which is in direct contrast to the ratio of nearly $100 \%$ calculated by Wada and Ou (2002). In fact these authors stated that boysenberries were unique in that essentially all of the EA present was in the free form. Casting doubt on these claims are the findings of Kool, Comeskey, Cooney, and McGhie (2010) who identified four different ellagitannins in samples of dry boysenberry powder, all in substantial concentrations. Furthermore, Furuuchi, Yokoyama, Watanabe, and Hirayama (2011) identified and quantified free EA and ET contents present in boysenberry seeds and juice calculating EA:ET percentages as $4.2 \%$ and $5.6 \%$ respectively. To offer an explanation for these inconsistencies between presented values when determining the free EA content of boysenberries, we measured the $\mathrm{pH}$ of the methanol-boysenberry extracting mixture (15 g of ground berries in $20 \mathrm{ml}$ methanol) used in the Wada and Ou (2002) study. Bearing in mind that ellagitannins are readily hydrolysed in an acidic environment to release the free form (Kool et al., 2010), the pH of the extraction was found to be 4.3. This low value together with the fairly rigorous extracting conditions ( $100 \%$ methanol at $100{ }^{\circ} \mathrm{C}$ for $24 \mathrm{~h}$ ) applied by these authors, suggests favourable ellagitannin hydrolysis conditions. Further evidence for this view was provided by Okuda, Yoshida, and Hatano (1989) who observed that higher temperatures for extended times caused the release of free EA from ETs. These factors in combination will concentrate the phenolic monomer giving rise to a considerable overestimation of the free EA content. 
Although all EA forms are believed to function as both in vitro and in vivo antioxidants their efficiency depends on their chemical structure, most notably the number of available hydroxyl groups (Pfundstein et al., 2010). Zafrilla et al. (2001) showed that free EA had the highest antioxidant activity (measured by its ability to neutralize the free radical 2,2-diphenyl-1-picrylhydrazyl, DPPH) of all the EA glycosides isolated from red raspberry. They attributed this to the fact that free EA has two dihydroxyl groups (Fig. 1a) compared to the isolated EA glycosides which have only one. An unidentified polymeric derivative (possibly an ET) showed double the activity of the free EA, probably due to a larger number of hydroxyls per molecule. The Pfundstein et al. (2010) study into Terminalia fruit phenolics (not including T. ferdinandiana) confirmed that the molar antioxidant capacity of the identified EA and ETs depended in part, on the number of hydroxyl groups per molecule. ETs (several containing up to 16 hydroxyl groups per molecule) possessed the highest activities as judged by the ORAC (Oxygen Radical Absorbance Capacity) and FRAP (Ferric Reducing Ability of Plasma) assays but interestingly, EA itself was ranked highly on a molar basis by the DPPH assay. The authors speculated this was due to the comparatively higher density of hydroxyls within the smaller EA molecule. This observation prompted the authors to state that a precise prediction of antioxidant activity based on the number of hydroxyls alone is not feasible.

As well as acting as an antioxidant, the absorption of EA forms in vivo is also influenced by their chemical structure. The degree of hydroxylation, glycosylation and polymerisation and hence solubility are considered to be the major factors (Karakaya, 2004). In a 2000 review, Clifford and Scalbert suggested that EA monomers were probably better absorbed than the high molecular weight ETs. However, several recent studies have indicated that the mechanisms of absorption of EA and ETs are more complex (Borges et al., 2007; Mertens-Talcott, Jilma-Stohlawetz, Rios, Hingorani, \& Derendorf, 2006). To date there are no definitive studies on the absorption of free EA, EA glycosides and ETs in humans. Not even the absorption of the free form has been demonstrated unequivocally (Landete, 2011). Recent research has suggested that some ETs are hydrolysed in vivo to yield EA which can then be absorbed and metabolised (reviewed by Crozier et al., 2009). Other studies (Espin et al., 2007; Seeram et al., 2006) have indicated that ETs are metabolised in the colon by the gut flora to produce urolithins which are subsequently absorbed. Although studies on the bioavailability of EA and ETs gained from these studies have increased our understanding, there is a vital need for further animal and human trials to demonstrate the operating mechanisms of this complex process. Regardless of this paucity of data, it is clear that EA structure will have a significant effect on its bioavailability.

\section{2. $A A$ and $D H A A$ content}

The AA contents were $459 \pm 21,6 \pm 2$ and $11863 \pm 1895 \mathrm{mg} / 100 \mathrm{~g}$ DW in strawberries, boysenberries and the Kakadu plum, respectively. Our values for strawberries were lower than those reported by Chebrolu, Jayaprakasha, Yoo, Jifon, and Patil (2012). OdriozolaSerrano, Hernández-Jover, and Martín-Belloso (2007) and the USDA National Nutrient Database quote 540, 586 and $650 \mathrm{mg} / 100 \mathrm{~g}$ DW, respectively, but Gökmen et al. (2000) found only $320 \mathrm{mg} / 100 \mathrm{~g}$ DW. We used $90.95 \%$ from the USDA National Nutrient Database (2013) for the water content of strawberries to convert results to a dry weight basis. The strawberry cultivar was not specified in the above mentioned investigations. Our value for the frozen boysenberries was much lower than the $21 \mathrm{mg} / 100 \mathrm{~g}$ DW given in the USDA National Nutrient Database (2013), converted to a dry weight basis by the use of a water content of $85.95 \%$. Our Kakadu plum AA content was higher than that published earlier (Konczak et al., 2009) of $7252 \mathrm{mg} / 100 \mathrm{~g} \mathrm{DW}$, but was in the range of $50-32220 \mathrm{mg} / 100 \mathrm{~g}$ DW (average value of 15190 ) reported in a more recent study of 567 samples of Kakadu plum (Konczak et al., 2014).
The DHAA values were $44 \pm 14,31 \pm 3$ and $2175 \pm 598 \mathrm{mg} / 100 \mathrm{~g}$ DW for the strawberry, boysenberry and Kakadu plum extracts, respectively. DHAA usually represents about $10-20 \%$ of the total vitamin C content in fruit (Borowski, Szajdek, Borowska, Ciska, \& Zielinski, 2008) and is considered to be the first compound produced in the oxidative degradation of AA (Chang, Lin, Chang, \& Liu, 2006). In the present study, DHAA represented $9.5,83$ and $23.2 \%$ of the vitamin C (AA + DHAA) content in strawberries, boysenberries and Kakadu plum (Table 1; Fig. 2). The contribution of DHAA reported in the literature (Gökmen et al., 2000; Odriozola-Serrano et al., 2007) for fresh strawberries (cultivars not specified) of 16.0 and $15.9 \%$, respectively, is similar to our result. The value for boysenberries suggests protracted processing and storage leading to a high transformation of AA to DHAA. On the basis of the high levels of DHAA in Kakadu plum, i.e. $>20 \%$, and the elevated levels of AA and EA, further examination was warranted.

\subsection{Storage trial of whole Kakadu plum fruit}

The results of free EA content and the bioactive vitamin C levels of frozen whole Kakadu plum fruit are shown in Table 3. The initial concentrations of both phytochemicals in this storage trial are consistent with values for the unstored samples (Tables 1 and 2). The values in the stored samples were marginally higher possibly because the seed was removed prior to analysis in the storage trial.

There were only minor changes in free EA content during frozen storage - in fact storage for nearly five months was necessary before there was a significant increase (Table 3 ). This was a surprising result because most researchers have reported almost immediate increases due to hydrolysis of the fruit ETs (Aaby, Wrolstad, Ekeberg, \& Skrede, 2007; Oszmianski et al., 2009). The latter study reported higher free EA levels in frozen strawberries than those present in the fresh sample. A similar effect was noted by Aaby et al. (2007) during the frozen storage of strawberry puree and room temperature storage of raspberry jam by Zafrilla et al. (2001). Interestingly Oszmianski et al. (2009) observed no significant increase in free EA content for 6 month frozen stored strawberries if a pre-freezing treatment that included AA was applied. Also it should be remembered that the high total acid content in conjunction with the low pH exhibited by the Kakadu plum fruit extracts would provide an environment conducive to the hydrolysis of the ETs even under frozen storage conditions (Table 1 ).

A significant immediate increase $(\mathrm{p}<0.05)$ in DHAA indicates considerable oxidation of AA to DHAA with storage. AA has often been added to fruit preserves mainly for its pronounced antioxidant properties but not to products where its reaction with anthocyanins leads to a loss of colour and quality (Oszmianski et al., 2009). As well, its addition has been shown to be useful as a polyphenol oxidation protector during the freezing, storage and thawing processes of a variety of food products (Oszmianski et al., 2009). Several investigations measuring polyphenol content have suggested that added AA prevented the oxidation of these compounds even during alkaline hydrolysis (Nardini et al., 2002). Our findings and the knowledge that AA is easily oxidisable and is often considered a terminal oxidant (Halliwell, 1994), suggest a protective effect of Kakadu plum EA by its elevated AA levels. It would also appear that this effect may even reduce the rate of hydrolysis of the ETs to free EA during frozen storage.

Table 1

Moisture (g/100 g), pH, titratable acidity (g/100 ml) and total vitamin C (mg/100 g DW) content of freeze-dried fruit powders. Values are means \pm SD of triplicate analyses.

\begin{tabular}{lllll}
\hline Fruit type & $\begin{array}{l}\text { Moisture } \\
(\mathrm{g} / 100 \mathrm{~g})\end{array}$ & $\mathrm{pH}$ & $\begin{array}{l}\text { Titratable acidity } \\
(\mathrm{g} / 100 \mathrm{ml})\end{array}$ & $\begin{array}{l}\text { Total vit. C } \\
(\mathrm{mg} / 100 \mathrm{~g} \mathrm{DW})\end{array}$ \\
\hline Strawberry & 2.03 & 3.9 & 0.64 & $503 \pm 25$ \\
Boysenberry & 3.81 & 3.5 & 1.07 & $37 \pm 2$ \\
Kakadu plum & 3.12 & 2.9 & 1.30 & $14038 \pm 701$
\end{tabular}




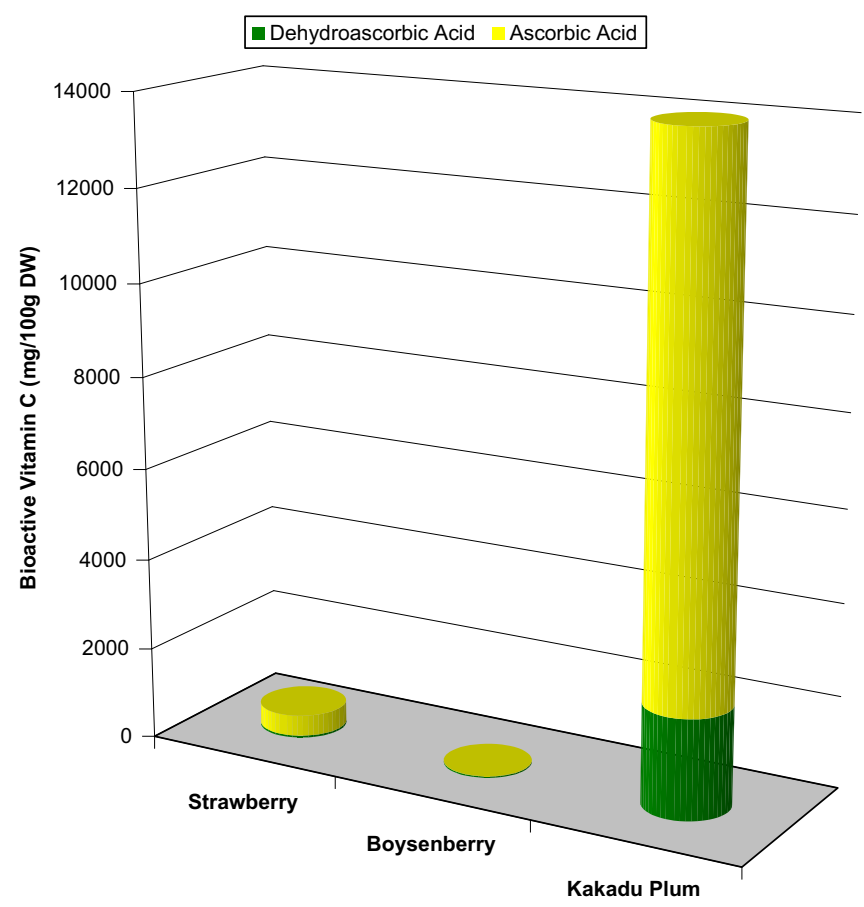

Fig. 2. Total vitamin C (ascorbic, AA + dehydroascorbic acid, DHAA) content in strawberries, boysenberries and whole Kakadu plum fruit. Values used are means of triplicate analyses.

\section{Conclusions}

The overall structural diversity of the different forms of EA has a pronounced effect on its antioxidant efficiency, solubility and hence its bioavailability. In this study the profile of these EA forms were determined obtaining much needed data that enables a more reliable interpretation of the plants' antioxidant capacity. Consistent with previous results the strawberry cultivar Camarosa contained mostly water soluble ETs. In frozen boysenberries we detected also mainly ETs with only minor amounts of free EA and EA glycosides. In Kakadu plum the major form was free EA and the levels were very high with no EA glycosides being detected. Based on studies to date and our results, fruit containing elevated levels of ETs and perhaps to a lesser extent free EA should possess high antioxidant activity. This would apply to strawberries and boysenberries and even though it possesses a smaller proportion of ETs than the other tested fruit, the very high free EA levels should bestow on the fruit of this plant exceptional antioxidant properties. A finding already noted in the investigations of Konczak et al. (2009) and Netzel, Netzel, Tian, Schwartz, and Konczak (2007). However it should be emphasised before claiming any antioxidant-related benefit of dietary EA a more in-depth understanding of the bioavailability of the different forms is critical.

Table 2

Concentration of EA forms (mg/100 g DW) in freeze-dried fruit powders. Values are means \pm SD of triplicate analyses.

\begin{tabular}{|c|c|c|c|c|}
\hline Fruit type & $\begin{array}{l}\text { Free EA } \\
(\mathrm{mg} / 100 \mathrm{~g} \mathrm{DW})\end{array}$ & $\begin{array}{l}\text { EA glycosides } \\
(\mathrm{mg} / 100 \mathrm{~g} \mathrm{DW})\end{array}$ & $\begin{array}{l}\text { Ellagitannins* } \\
\text { (mg/100 g DW) }\end{array}$ & $\begin{array}{l}\text { Free EA/Total } \\
\text { EA } \\
(\%)\end{array}$ \\
\hline Strawberry & $4.8 \pm 0.1$ & $8.8 \pm 0.7$ & $50.7 \pm 1.7$ & 7.4 \\
\hline Boysenberry & $5.5 \pm 0.6$ & $15.3 \pm 0.3$ & $147.6 \pm 3.2$ & 3.2 \\
\hline $\begin{array}{l}\text { Kakadu plum } \\
\text { fruit }\end{array}$ & $620.7 \pm 2.2$ & N.D. & $259.1 \pm 12.9$ & 70.6 \\
\hline
\end{tabular}

N.D. - not detected.

*Calculated by subtracting the free and EA glycoside levels from the total EA content measured after acid hydrolysis.
Table 3

The free EA content (mg/100 g DW) and the \% contribution of DHAA to total vitamin C levels of freezer stored whole (without seed) Kakadu plum fruit. Values are means \pm SD of triplicate analyses.

\begin{tabular}{lll}
\hline Storage (months) & $\begin{array}{l}\text { Free EA content } \\
(\mathrm{mg} / 100 \mathrm{~g} \mathrm{DW})\end{array}$ & $\begin{array}{l}\text { DHAA/Total vitamin C } \\
(\%)\end{array}$ \\
\hline 0 & $980 \pm 10^{\mathrm{a}}$ & $9.4 \pm 0.5^{\mathrm{a}}$ \\
1 & $972 \pm 11^{\mathrm{a}}$ & $12.8 \pm 0.6^{\mathrm{b}}$ \\
4 & $922 \pm 12^{\mathrm{b}}$ & $13.8 \pm 0.5^{\mathrm{b}}$ \\
5 & $1048 \pm 17^{\mathrm{c}}$ & $17.2 \pm 0.6^{\mathrm{c}}$ \\
8 & $1069 \pm 12^{\mathrm{c}}$ & $17.0 \pm 0.2^{\mathrm{c}}$ \\
\hline
\end{tabular}

For the two columns means followed by a common letter are not significantly different at $\mathrm{p}=0.050$. AA, ascorbic acid; EA, ellagic acid; DHAA, dehydroascorbic acid.

Kakadu plum fruit also has far higher concentrations of AA and DHAA than the other fruits tested. Our findings for the frozen stored Kakadu plum samples are consistent with a possible protective effect of EA by ascorbic acid. This is one of the first studies that offers evidence of this effect by the plants' endogenous ascorbic acid on its EA based compounds. Further research on other fruit or vegetables with high free EA and vitamin C contents may strengthen this argument.

\section{Acknowledgements}

This work was supported by the Rural Industries Research and Development Corporation (RIRDC, Australia).

The authors wish to thank the following people for providing informed comments and suggestions: Emeritus Professor Christa Critchley, Dr. Izabela Konczak of Food \& Nutritional Sciences, CSIRO, Dr. Heather Smyth, Queensland Alliance for Agriculture and Food Innovation (QAAFI), The University of Queensland, as well as a large contribution to proof-reading the manuscript.

\section{References}

Aaby, K., Skrede, G., \& Wrolstad, R. E. (2005). Phenolic composition and antioxidant activities in flesh and achenes of strawberries (Fragaria anananassa). Journal of Agricultural and Food Chemistry, 53, 4032-4040.

Aaby, K., Wrolstad, R. E., Ekeberg, D., \& Skrede, G. (2007). Polyphenol composition and antioxidant activity in strawberry purees: impact of achene level and storage. Journal of Agricultural and Food Chemistry, 55, 5156-5166.

Amakura, Y., Okada, M., Tsuji, S., \& Tonogai, Y. (2000). High-performance liquid chromatographic determination with photodiode array detection of ellagic acid in fresh and processed fruits. Journal of Chromatography A, 896, 87-93.

Association of Official Analytical Chemists (1995). Official Methods of AOAC International Official Method 964.22 (14th ed.). Arlington, VA: Association of Official Analytical Chemists International.

Atkinson, C. J., Nestby, R., Ford, Y. Y., \& Dodds, P. A. A. (2005). Enhancing beneficial antioxidants in fruits: A plant physiological perspective. BioFactors, 23, 229-234.

Borges, G., Roowi, S., Rouanet, J. M., Duthie, G. G., Lean, M. E. J., \& Crozier, A. (2007). The bioavailability of raspberry anthocyanins and ellagitannins in rats. Molecular Nutrition \&' Food Research, 51, 714-725.

Borowski, J., Szajdek, A., Borowska, E. J., Ciska, E., \& Zielinski, H. (2008). Content of selected bioactive components and antioxidant properties of broccoli (Brassica oleracea L.). European Food Research and Technology, 226, 459-465.

Chang, C. H., Lin, H. Y., Chang, C. Y., \& Liu, Y. C. (2006). Comparisons on the antioxidant properties of fresh, freeze-dried and hot-air-dried tomatoes. Journal of Food Engineering, 77, 478-485.

Chebrolu, K. K., Jayaprakasha, G. K., Yoo, K. S., Jifon, J. L., \& Patil, B.S. (2012). An improved sample preparation method for quantification of ascorbic acid and dehydroascorbic acid by HPLC. Food Science and Technology, 47, 443-449.

Clifford, M. N., \& Scalbert, A. (2000). Ellagitannins - native, occurrence and dietary burden. Journal of the Science of Food and Agriculture, 80, 1118-1125.

Crozier, A., Jaganath, I. B., \& Clifford, M. N. (2009). Dietary phenolics: chemistry, bioavailability and effects on health. Natural Product Reports, 26, 1001-1043.

Cunningham, A. B., Garnett, S., Gorman, J., Courtney, K., \& Boehme, D. (2009). Ecoenterprises and Terminalia ferdinandiana: "Best laid plans" and Australian policy lessons. Economic Botany, 63, 16-28.

da Silva Pinto, M., Lajolo, F. M., \& Genovese, M. I. (2008). Bioactive compounds and quantification of total ellagic acid in strawberries. Food Chemistry, 107, 1629-1635.

Dennison, D. B., Brawley, T. G., \& Hunter, G. L. K. (1981). Rapid high-performance liquid chromatographic determination of ascorbic acid and combined ascorbicdehydroascorbic acid in beverages. Journal of Agricultural and Food Chemistry, 29, 927-929.

Espin, J. C., González-Barrio, R., Cerdá, B., López-Bote, C., Rey, A. I., \& Tomás-Barberán, F. A. (2007). Iberian pig as a model to clarify obscure points in the bioavailability and 
metabolism of ellagitannins in humans. Journal of Agricultural and Food Chemistry, 55, 10476-10485.

Fredrich, J. E. (2005). Titratable activity of acid tastants. In R. E. Wrolstad (Eds.), Handbook of food analytical chemistry (pp. 343-349). New Jersey: John Wiley \& Sons.

Furuuchi, R., Yokoyama, T., Watanabe, Y., \& Hirayama, M. (2011). Identification and quantification of short oligomeric proanthocyandins and other polyphenols in boysenberry seeds and juice. Journal of Agricultural and Food Chemistry, 59, 3738-3746.

Gasperotti, M., Masuero, D., Vrhovsek, U., Guella, G., \& Mattivi, F. (2010). Profiling and accurate quantification of Rubus ellagitannins and ellagic acid conjugates using direct UPLC-Q-TOF HDMS and HPLC-DAD analysis. Journal of Agricultural and Food Chemistry, 58, 4602-4616.

Gökmen, V., Kahraman, N., Demir, N., \& Acar, J. (2000). Enzymatically validated liquid chromatographic method for the determination of ascorbic and dehydroascorbic acids in fruit and vegetables. Journal of Chromatography A, 881, 309-316.

Häkkinen, S. H., \& Törrönen, A.R. (2000). Content of flavonols and selected phenolic acids in strawberries and Vaccinuim species: Influence of cultivar, cultivation site and technique. Food Research International, 33, 517-524.

Halliwell, B. (1994). Free radicals and antioxidants: a personal view. Nutrition Reviews, 52, 253-265.

Hoare, M., Jones, S., \& Lindsay, J. (1993). Total vitamin C analysis of orange juice. Food Australia, 45, 341-345.

Karakaya, S. (2004). Bioavailability of phenolic compounds. Critical Reviews in Food Science and Nutrition, 44, 453-464.

Konczak, I., Maillot, F., \& Dalar, A. (2014). Phytochemical divergence in 45 accessions of Terminalia ferninandiana (Kakadu plum). Food Chemistry, 151, 248-256.

Konczak, I., Zabaras, D., Dunstan, M., Aguas, P., Roulfe, P., \& Pavan, A. (2009). Health benefits of Australian native foods: an evaluation of health-enhancing compounds. Australian Government, RIRDC, Pub. No. 09/133, 20.

Kool, M. M. Comeskey, D. J., Cooney, J. M. \& McGhie, T. K. (2010). Structural identification of the main ellagitannins of a boysenberry (Rubus loganbaccus $x$ baileyanus Britt.) extract by LC-ESI-MS/MS, MALDI-TOF-MS and NMR spectroscopy. Food Chemistry, 119, 1535-1543.

Landete, J. M. (2011). Ellagitannins, ellagic acid and their derived metabolites: A review about source, metabolism, function and health. Food Research International, 44, 1150-1160.

Maas, J. L., Wang, S. Y., \& Galletta, G. J. (1991). Evaluation of strawberry cultivars for ellagic acid content. HortScience, 26, 66-68.

Mertens-Talcott, S., Jilma-Stohlawetz, P., Rios, J., Hingorani, L., \& Derendorf, H. (2006). Absorption, metabolism and antioxidant effects of pomegranate polyphenols after ingestion of a standardized extract in healthy human volunteers. Journal of Agricultural and Food Chemistry, 54, 8956-8961.
Nardini, M., Cirillo, E., Natella, F., Mencarelli, D., Comisso, A., \& Scaccini, C. (2002). Detection of bound phenolic acids: prevention by ascorbic acid and ethylenediaminetetraacetic acid of degradation of phenolic acids during alkaline hydrolysis. Food Chemistry, 79, 119-124

Netzel, M., Netzel, G., Tian, Q., Schwartz, S., \& Konczak, I. (2007). Native Australian fruits a novel source of antioxidants for food. Innovative Food Science and Emerging Technologies, 8, 339-346.

Odriozola-Serrano, I., Hernández-Jover, T., \& Martín-Belloso, O. (2007). Comparative evaluation of UV-HPLC methods and reducing agents to determine vitamin $\mathrm{C}$ in fruits. Food Chemistry, 105, 1151-1158.

Okuda, T., Yoshida, T., \& Hatano, T. (1989). New methods of analyzing tannins. Journal of Natural Products, 52, 1-31.

Oszmianski, J., Wojdyło, A., \& Kolniak, J. (2009). Effect of L-ascorbic acid, sugar, pectin and freeze-thaw treatment on polyphenol content of frozen strawberries. Food Science and Technology, 42, 581-586.

Pfundstein, B., El Desouky, S. K., Hull, W. E., Haubner, R., Erben, G., \& Owen, R. W. (2010) Polyphenolic compounds in the fruits of Egyptian medicinal plants (Terminalia ballerica, Terminalia chebula and Terminalia horrida): Characterisation, quantitation and determination of antioxidant capacities. Phytochemistry, 71, 1132-1148.

Rommel, A., \& Wrolstad, R. E. (1993). Influence of acid and base hydrolysis on the phenolic composition of red raspberry juice. Journal of Agricultural and Food Chemistry, 41, 1237-1241.

Seeram, N.P., Henning, S. M., Zhang, Y., Suchard, M., Li, Z., \& Heber, D. (2006). Promegranate juice ellagitannin metabolites are present in human plasma and some persist in urine for up to 48 hours. The Journal of Nutrition, 136, 2481-2485.

Tomás-Barberán, F. A., \& Andrés-Lacueva, C. (2009). Polyphenols and health: Current state and progress. Journal of Agricultural and Food Chemistry, 60, 8773-8775.

Tomás-Barberán, F. A. Somoza, V. \& Finley, J. (2009). Food bioactives research and the Journal of Agricultural and Food Chemistry. Symposium Introduction. Journal of Agricultural and Food Chemistry, 60, 6641-6643.

U.S. Department of Agriculture, Agricultural Research Service (2013). USDA National Nutrient Database for Standard Reference, Release 26. Nutrient Data Laboratory Home Page (http://www.ars.usda.gov/ba/bhnrc/ndl).

Wada, L., \& Ou, B. (2002). Antioxidant activity and phenolic content of Oregon caneberries. Journal of Agricultural and Food Chemistry, 50, 3495-3500.

Willett, W. C. (2002). Balancing life-style and genomics research for disease prevention Science, 296, 695-698.

Zafrilla, P., Ferreres, F., \& Tomas-Barberan, F. A. (2001). Effect of processing and storage on the antioxidant ellagic acid derivatives and flavonoids of red raspberry jams. Journal of Agricultural and Food Chemistry, 49, 3651-3655. 